Revista Brasileira de Agricultura Irrigada v.7, nº 1, p. 42 - 53, 2013

ISSN 1982-7679 (On-line)

Fortaleza, CE, INOVAGRI - http://www.inovagri.org.br

DOI: $10.7127 /$ rbai.v7n100102

Protocolo 102.12 - 15/10/2012 Aprovado em 11/02/2013

\title{
LÂMINAS DE IRRIGAÇÃO E FREQUÊNCIA DE APLICAÇÃO NO CRESCIMENTO DO MELOEIRO
}

\author{
Manoel Valnir Júnior ${ }^{1}$; Vera Lúcia Antunes de Lima² ${ }^{2}$ Raimundo Rodrigues Gomes Filho ${ }^{3}$, \\ Clayton Moura de Carvalho ${ }^{4}$, Frederico Antônio Loureiro Soares ${ }^{5} \&$ Sílvio Carlos Ribeiro \\ Vieira Lima ${ }^{6}$
}

\section{RESUMO}

Objetivou-se estudar o crescimento da parte área do melão submetido aos efeitos de lâminas de irrigação e freqüências d'água por gotejamento. No Distrito de Irrigação Baixo Acaraú, montou-se um experimento utilizando o delineamento experimental em blocos casualizado com 20 tratamentos e 3 blocos em esquema fatorial 4 x 3. Os tratamentos resultam da combinação de 5 lâminas de irrigação $\left(\mathrm{L}_{1}=60 \%, \mathrm{~L}_{2}=80 \%, \mathrm{~L}_{3}=100 \%, \mathrm{~L}_{4}=120 \%\right.$ e $\mathrm{L}_{5}=140 \%$ da ETc) e de 4 frequiências de aplicação de água $\left(\mathrm{F}_{1}=\right.$ a lâmina fracionada em 3 vezes ao dia, $\mathrm{F}_{2}=$ a lâmina fracionada em 2 vezes ao dia, $\mathrm{F}_{3}=$ a lâmina aplicada em uma única vez ao dia e $\mathrm{F}_{4}=$ a lâmina em uma única vez em dias alternados). A quantidade de água aplicada foi determinada mediante a necessidade de reposição das perdas decorrentes da evapotranspiração da cultura através do tanque classe A. Verificou-se que os fatores lâminas e frequência de irrigação foram indiferentes à característica número de folhas; A lâmina fez efeito na variável área foliar apenas aos 41 DAS; A lâmina fez efeito na variável área foliar apenas aos 41 DAS; A maior produção de matéria seca pelo meloeiro está condicionada as maiores lâminas de irrigação; o maior e o menor incremento de matéria seca, durante a fase de crescimento, foram obtidos com as lâminas de 266,19 e 159,41 mm, respectivos a 94,36 e $83,20 \%$; o aumento diário de matéria seca aumentou proporcionalmente à lâmina de irrigação aplicada até 41 dias após semeadura.

Palavras-chaves: Cucumis melo, desenvolvimento vegetativo, matéria seca.

\section{INFLUENCE OF DIFFERENT WATER DEPTH AND IRRIGATION FREQUENCY ON GROWTH OF MELON}

\author{
ABSTRACT

\footnotetext{
${ }^{1}$ Dr. em Irrigação e Drenagem, Prof. do IFCE Sobral, e-mail: valnirjvm@yahoo.com.br

${ }^{2}$ Dra. em Irrigação e Drenagem, Profa. da UFCG.

${ }^{3}$ Dr. em Irrigação e Drenagem, Prof. da UFG, e-mail: rrgomesfilho@ @otmail.com

${ }^{4}$ Dr. em Irrigação e Drenagem, Prof. da FATEC Cariri, e-mail: carvalho_cmc@ yahoo.com.br

${ }^{5}$ Dr. em Irrigação e Drenagem, Prof. do IF Goiano

${ }^{6}$ Dr. em Irrigação e Drenagem, INOVAGRI, e-mail: scrvlima@ hotmail.com
} 


\section{LÂMINAS DE IRRIGAÇÃO E FREQUÊNCIA DE APLICAÇÃO NO CRESCIMENTO DO MELOEIRO}

The objective was to study the growth of the area of melon subjected to the effects of irrigation frequency and water drip. In Irrigation District Baixo Acaraú, set up an experiment using the experimental design in randomized blocks with 20 treatments and 3 blocks in a factorial $4 \times 3$. The treatments resulting from the combination of 5 irrigation levels $\left(\mathrm{L}_{1}=60 \%\right.$, $\mathrm{L}_{2}=80 \%, 100 \%=\mathrm{L}_{3}, \mathrm{~L}_{4}$ and $\mathrm{L}_{5}=120 \%=140 \%$ of ETc) and 4 rates of application of water $\left(\mathrm{F}_{1}=\right.$ a blade split in 3 times a day, $\mathrm{F}_{2}=$ the blade split in 2 times a day, $\mathrm{F}_{3}=$ applied to the blade once a day, and $\mathrm{F}_{4}=$ a slide in once on alternate days). The amount of water applied was determined by the need for replacement of losses of crop evapotranspiration by tank Class A. It was found that the factors blades and irrigation frequency characteristic were indifferent to the number of sheets; blade made variable effect on leaf area only to DAS 41; blade made variable effect on leaf area only to DAS 41; Most matter production dried melon is conditioned by the higher irrigation, the largest and the smallest increment of dry matter during the growth phase, were obtained with the blades of 266.19 and $159.41 \mathrm{~mm}$, corresponding to 94.36 and $83.20 \%$, the increase in daily dry matter intake increased proportionally to the applied irrigation depth up to 41 days after sowing.

Keywords: Cucumis melo, vegetative development, dry substance.

\section{INTRODUÇÃO}

O melão é uma das espécies de maior importância econômica da família Curcubitaceae, por possuir uma grande variabilidade genética, em virtude das exportações do melão vem aumentando esta importância econômica no Brasil (SANTOS et al., 2004). Segundo Campelo et al. (2012) o melão é a principal fruta, olerícola, exportada pelo estado do Ceará. No biênio 2008/09, as exportações dessa olerícola alcançaram um total de US\$ 159,8 milhões. No ano de 2010, o melão liderou as exportações cearenses com um valor de US\$ 74,2 milhões.

No semiárido brasileiro são grandes as potencialidades para a fruticultura irrigada, pelas peculiaridades, como temperaturas elevadas e luminosidade durante praticamente o ano inteiro. Dentre os cultivos se destaca o melão (Cucumis melo L.), responsável por cerca de $92 \%$ de toda a produção nacional (IBGE, 2010; TERCEIRO NETO et al., 2012 ).

O Nordeste possui condições edafoclimáticas, exceto pluviosidade, favoráveis, como temperatura, luminosidade e umidade relativa do ar adequados ao crescimento e à produção de muitas olerícolas, inclusive o melão. Por ser cultivada no período seco, a irrigação é prática limitante ao sistema de produção comercial da cultura. Apesar disso, a irrigação na região ainda carece de estudos para manifestar sua total potencialidade, necessitando de melhor controle quanto à quantidade de água a ser aplicada, à frequência e ao momento crítico de irrigação (SOUSA et al., 2010).

O manejo da água, em função de lâminas e frequência de aplicação adequados à cultura do meloeiro constitui meta o rendimento economicamente viável. Apesar do Brasil ocupar posição de destaque no cenário mundial, no que diz respeito à disponibilidade d'água, variabilidade climática nas diversas regiões que o compõe caracteriza distintos potenciais para o uso na agricultura irrigada. Dentre as regiões brasileiras, o Nordeste revela-se a mais viável em condições nesta prática agrícola, contudo, essa realidade é um contra-senso quando comparado ao volume d'água disponível nesta região (VALNIR JÚNIOR et al., 2009).

A lâmina d'água e a maneira como é fornecida às plantas é de suma importância na definição de manejo de uma cultura; erros ou negligências nesses pontos muitas vezes geram insucessos da produção tornando os cultivos economicamente inviáveis (COELHO et al., 2005). Tal 


\section{LÂMINAS DE IRRIGAÇÃO E FREQUÊNCIA DE APLICAÇÃO NO CRESCIMENTO DO MELOEIRO}

relevância condiciona a estimativa desses fatores às condições específicas de cada localidade, devido as variações climáticas e físico-hídricas dos solos.

Mesmo admitindo a reconhecida importância da irrigação no processo produtivo, a baixa eficiência na condução da água e na aplicação aos cultivos, motiva um esforço na otimização do uso da água, onde o enfoque da eficiência produtiva deve ser priorizado, a partir da medição de toneladas de alimentos produzidos por metro cúbico de água, em vez da produção por unidade de área (MONTEIRO et al., 2008).

Um dos fatores indispensáveis para o avanço e sucesso na produção da cultura do melão é o manejo da irrigação, tanto na produtividade como na qualidade dos frutos, os parâmetros climáticos como temperatura, umidade reativa, insolação e velocidade do vento, associado ao estádio fenológico das culturas, textura, cobertura do solo e índice de área foliar, são variáveis determinantes no cálculo da necessidade de água à cultura e a frequência de irrigação (ALLEN et al., 1998; COSTA et al., 2000; SILVA et al., 2012).

Pelo exposto, o trabalho teve como objetivo avaliar o crescimento vegetativo, pela produção de biomassa da parte aérea do meloeiro irrigado com diferentes lâminas de água e frequência de aplicação, em diferentes idades fenológicas das plantas de melão.

\section{MATERIAL E MÉTODOS}

O experimento foi instalado e conduzido em área particular no Distrito de Irrigação do Baixo Acaraú, situado na região norte do Estado do Ceará, no trecho final da bacia do Rio Acaraú. O clima da região é, conforme a classificação de Thornthwaite \& Mather (1955), do tipo Aw Tropical Chuvoso, que representa clima quente, com precipitação média anual de $900 \mathrm{~mm}$, concentradas nos meses de janeiro a junho, temperaturas: mínima, média e máxima anual de $22,8,28,1$ e $34,7{ }^{\circ} \mathrm{C}$, respectivamente. Insolação de $2.650 \mathrm{~h}^{2} \mathrm{ano}^{-1}$, umidade relativa média anual de $70 \%$, velocidade média dos ventos de $3 \mathrm{~m} \mathrm{~s}^{-1} \mathrm{e}$ evaporação média anual de $1.600 \mathrm{~mm}$.

O preparo do solo constou de uma aração, uma gradagem, abertura dos sulcos e confecção dos camalhões de plantio com grade enleiradeira na faixa de solo onde foram inseridas as fileiras de plantas.

As análises de solo foram realizadas no laboratório de Solos e Água do Departamento de Ciências do Solo da Universidade Federal do Ceará, conforme metodologias propostas por EMBRAPA (1997). Os resultados da análise química serviram de base às adubações de fundação e de cobertura ao longo do ciclo da cultura.

Foram utilizadas sementes de melão (Cucumis melo L), originadas da Petoseed ${ }^{\circledR}$, var. inodorus, cv. F1 10/00 do tipo "amarelo".

O delineamento experimental foi blocos ao acaso, em três repetições, usando a arranjo fatorial $5 \times 4 \times 3$, referente as lâmnas de irrigação, frequências de aplicação e idades de avaliação das plantas. As lâminas de irrigação foram de 0,$6 ; 0,8$; 1,$0 ; 1,2$ e 1,4 vezes a evapotranspiração da cultura $\left(\mathrm{ETc}_{\mathrm{L}}\right)$, cada uma na frequência de aplicação d'água. As parcelas experimentais mediam $60 \mathrm{~m}^{2}(10 \times 6 \mathrm{~m})$, totalizando 24 plantas por fileira. Cada bloco tinha uma área de 0,12 ha resultando em uma área efetiva de 0,36 ha.

As frequências de irrigação foram a três, duas e uma vez ao dia e a última frequência em dias alternados. As plantas foram avaliadas aos 27, 41 e 55 dias após a semeadura - DAS. O sistema de irrigação utilizado foi do tipo gotejamento, com emissores na linha trabalhando a uma pressão média de $150 \mathrm{kPa}$ e vazão nominal de $2,3 \mathrm{~L} \mathrm{~h}^{-1}$, sendo um emissor para cada duas plantas.

O tempo de aplicação d'água, utilizado na diferenciação dos tratamentos adotados, de acordo com o nível e a 


\section{LÂMINAS DE IRRIGAÇÃO E FREQUÊNCIA DE APLICAÇÃO NO CRESCIMENTO DO MELOEIRO}

frequência de irrigação, foi determinado pela Eq. 1.

$$
T_{\text {IRRIGAÇÃO }}=\frac{\left[\frac{\left(\frac{E T c_{L} \cdot F_{L} \cdot 0,5.60}{q_{\text {gotejador }}}\right) \times \text { Freq }}{E f}\right]}{N_{\text {gotejadores }}}
$$

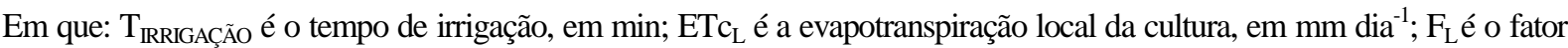
lâmina de irrigação $\left(0,6,0,8,1,0,1,2\right.$ e 1,4 da $\left.\mathrm{ETc}_{\mathrm{L}}\right)$; Freq. é o fator frequência de aplicação de água; qgotejador é a vazão do gotejador, em $\mathrm{L} \mathrm{h}^{-1}$; Ef é a eficiência do sistema; $\mathrm{N}$ é o número de gotejadores.

A análise de crescimento da parte aérea foi avaliada através da retirada de 1 (uma) planta de cada parcela, em competição plena, nos $27^{\circ}, 41^{\circ}$ e $55^{\circ}$ dias após a semeadura (DAS), a partir de plantas localizadas nas duas fileiras adjacentes à fileira central. As características avaliadas foram: número de folhas (NF), área foliar (AF), matéria seca da parte aérea (MSPA).

A área foliar total das plantas foi estimada através da técnica do uso de um fator de correção, preconizada por Benincasa (1988). As folhas vivas e inteiramente distendidas foram destacadas das hastes, cujos limbos foram separados do pecíolo, obtendose ao final a área foliar total da planta $\mathrm{em} \mathrm{cm}^{2}$.

Cada planta amostrada foi subdividida em hastes (caules), folhas, pecíolo e flores e, em seguida, estes órgãos foram devidamente acondicionados em sacos de papel e posteriormente levados à estufa de circulação forçada de ar a $65{ }^{\circ} \mathrm{C}$, onde foram secos até atingirem massa constante.

Os efeitos dos fatores lâmina de irrigação e frequência de aplicação de água sobre as variáveis estudadas, geraram dados que foram interpretados mediante a análise de variância simples teste " $F$ " e regressão, com auxílio do software SISVAR. Por serem fatores quantitativos realizou-se análise de regressão polinomial (linear, quadrática e cúbica), objetivando correlacionar o modelo matemático que melhor se ajuste (FERREIRA, 2000 e RIBEIRO JÚNIOR, 2001).

Em virtude, da ausência de normalidade dos dados e pela a não homogeneidade estatística nas variâncias das diferentes amostras, optou-se em transformar os dados das variáveis número de folhas, área foliar, matéria seca da parte aérea em log X, matéria seca do pecíolo, flores, folhas e caule em $\sqrt{X+1}$.

\section{RESULTADOS E DISCUSSÃO}

Verifica-se, pelas análises de variância (Tabela 1), não ter havido efeito isolado $(p<0,01)$ dos fatores lâmina de irrigação (L) e frequência de aplicação de água (F) sobre o número de folhas por planta (NF) aos 27, 41 e 55 dias após semeadura (DAS). A relação interativa ( $\mathrm{L} x$ F) não resultou em diferença significativa, indicando que o efeito das lâminas de irrigação sobre o número de folhas do meloeiro independe da frequência de aplicação da água.

Tabela 1. Resumo das análises de variância referentes ao número de folhas (NF), área foliar (AF) e matéria seca da parte aérea (MSPA) do meloeiro var. inodoro do tipo "amarelo" cultivar híbrida F1 10/00, com diferentes lâminas de irrigação e frequência de aplicação de água em função de dias após semeadura

\begin{tabular}{|c|c|c|c|c|c|c|c|c|c|c|}
\hline \multirow{3}{*}{ Causa de variação } & \multirow{3}{*}{ GL } & \multicolumn{9}{|c|}{ Quadrados médio } \\
\hline & & \multicolumn{3}{|c|}{ NF } & \multicolumn{3}{|c|}{$\mathrm{AF}$} & \multicolumn{3}{|c|}{ MSPA } \\
\hline & & 27 & 41 & 55 & 27 & 41 & 55 & 27 & 41 & 55 \\
\hline Lâmina de irrigação (L) & 4 & $0,05^{\mathrm{NS}}$ & $0,05^{\mathrm{NS}}$ & $0,08^{\AA}$ & $0,12^{\mathrm{NS}}$ & $0,14 * *$ & $0,03^{\mathrm{Ns}}$ & $0,14^{\mathrm{NS}}$ & $0,10^{\mathrm{N}}$ & $0,04^{\mathrm{N}}$ \\
\hline
\end{tabular}




\section{LÂMINAS DE IRRIGAÇÃO E FREQUÊNCIA DE APLICAÇÃ̃O NO CRESCIMENTO DO MELOEIRO}

\begin{tabular}{|c|c|c|c|c|c|c|c|c|c|c|}
\hline Frequência de aplicação & 3 & $0,01^{\mathrm{NS}}$ & $0,01^{\mathrm{NS}}$ & $0,05^{\mathrm{N}}$ & $0,02^{\mathrm{NS}}$ & $0,01^{\mathrm{NS}}$ & $0,05^{\mathrm{NS}}$ & $0,01^{\mathrm{NS}}$ & $0,01^{\mathrm{N}}$ & $0,06^{\mathrm{N}}$ \\
\hline Interação L X F & 12 & $0,04^{\mathrm{NS}}$ & $0,02^{\mathrm{NS}}$ & $0,03^{\mathrm{N}}$ & $0,08^{\mathrm{NS}}$ & $0,02^{\mathrm{NS}}$ & $0,04^{\mathrm{NS}}$ & $0,08^{\mathrm{NS}}$ & $0,02^{\mathrm{N}}$ & $0,04^{\mathrm{N}}$ \\
\hline Bloco & 2 & $0,22 * *$ & $0,02^{\mathrm{NS}}$ & $0,05^{\mathrm{N}}$ & $0,24 * *$ & $0,01^{\mathrm{NS}}$ & $0,02^{\mathrm{NS}}$ & $0,28^{*}$ & $0,01^{\mathrm{N}}$ & $0,01^{\mathrm{N}}$ \\
\hline Resíduo & 38 & 0,03 & 0,03 & 0,06 & 0,05 & 0,04 & 0,07 & 0,07 & 0,04 & 0,07 \\
\hline $\mathrm{CV}$ & $(\Omega)$ & 13,35 & 10,34 & 14,02 & 6,37 & 5,60 & 7,05 & 25,34 & 16,07 & 20,53 \\
\hline Lâmina & \multicolumn{7}{|c|}{$\begin{array}{l}\text { Médias observadas }^{2} \\
\text {---- Unidade planta } \\
-1\end{array}$} & \multicolumn{3}{|c|}{----- $\mathrm{cm}^{2}$ planta $^{-1}$} \\
\hline $\mathrm{L}_{1}(15 \mathrm{~s}$ & & 23,67 & 37,33 & 64,67 & 2748,3 & 3130,4 & 4784,6 & 12,20 & 16,53 & 22,35 \\
\hline $\mathrm{L}_{2}(211,92 \mathrm{~mm})$ & & 25,25 & & 73,92 & 2346,7 & 4025,3 & 5175,3 & 12,89 & 22,05 & 24,60 \\
\hline $\mathrm{L}_{3}(266,19 \mathrm{~mm})$ & & 25,00 & 51,83 & 66,25 & 2732,7 & 5316,9 & 6099,5 & 13,80 & 25,99 & 26,82 \\
\hline $\mathrm{L}_{4}(319,10 \mathrm{~mm})$ & & 26,83 & 52,67 & 55,25 & 2797,7 & 5801,4 & 5564,3 & 12,99 & 27,31 & 24,97 \\
\hline $\mathrm{L}_{5}(372,38 \mathrm{~mm})$ & & 20,00 & 47,83 & 42,17 & 1734,1 & 5255,9 & 4236,7 & 8,97 & 25,24 & 18,00 \\
\hline $\mathrm{dms}$ & & 10,14 & 19,55 & 44,96 & 1225,2 & 2414,9 & 3902,8 & 6,97 & 11,62 & 18,72 \\
\hline Frequ & & \multicolumn{3}{|c|}{----- g planta $^{-1}$} & \multicolumn{3}{|c|}{---- Unidade planta ${ }^{-1}$} & \multicolumn{3}{|c|}{---- $\mathrm{cm}^{2}$ planta $^{-1}---$} \\
\hline $\mathrm{F}_{1}(3$ & & 22,60 & 47,27 & 47,80 & 2390,5 & 4771,5 & 4058,1 & 12,01 & 23,81 & 17,54 \\
\hline $\mathrm{F}_{2}(2 \mathrm{v}$ & & 24,40 & & 75,53 & 2286,2 & 4449,7 & 6191,2 & 12,05 & 21,93 & 28,34 \\
\hline $\mathrm{F}_{3}(1 \mathrm{ve}$ & & 26,00 & & 55,20 & 2560,6 & 4393,8 & 5009,8 & 12,38 & 22,67 & 23,66 \\
\hline $\mathrm{F}_{4}(\mathrm{dia}$ & & 23,60 & 48 & 63,27 & 2650,3 & 5209,0 & 5429,3 & 12,25 & 25,29 & 23,85 \\
\hline $\mathrm{dms}$ & & 8,51 & 16,40 & 37,73 & 1028,3 & 2026,8 & 3275,6 & 5,86 & 9,76 & 15,71 \\
\hline
\end{tabular}

$\mathrm{NS}=$ não significativo; $*$ =significativo a $5 \%$ de probabilidade $\mathrm{e}^{* *}=$ significativo a $1 \%$ de probabilidade pelo Teste $\mathrm{F} ;{ }^{1}$ dados transformados em $\log (N F) ;{ }^{2}$ médias originais.

De acordo com as médias (Tabela 1), o número de folhas aumentou no período de 27 aos 55 DAS, de 23,67 para 64,67 folhas planta ${ }^{-1}$ na menor lâmina aplicada $(159,41 \mathrm{~mm})$, gerando um ganho de 173,22\%; seguindo o mesmo raciocínio e para a mesma amplitude foram registrados incrementos de 192,74, 165,00, 105,90 e $110,83 \%$ quando se aplicou as lâminas totais de 211,92, 266,19, 319,10 e 372,38 $\mathrm{mm}$, respectivamente, evidenciando que o déficit hídrico não ocasiona redução do número de folhas da planta. Por outro lado, o excesso de água concorre para diminuição destas; conforme os percentuais de aumento, o número de folhas acumulada no tratamento de maior suprimento hídrico, foi $62,41 \%$ menor que o valor obtido com a aplicação de 159,41 mm de água.

Credita-se este maior ganho no número de folhas obtido na menor lâmina, ser devido a grande incidência de folhas emergidas no período correspondente ao intervalo entre a $2^{\mathrm{a}}$ e $3^{\mathrm{a}}$ avaliações (dos 42 aos 55 DAS), visto que dos 27 aos 41 DAS as plantas irrigadas com uma lâmina de $372,83 \mathrm{~mm}$, obteve a maior emergência de folhas, cerca de 27,83 folhas em 14 dias, ou seja, a cada dia emergia 1,99 folhas, enquanto na lâmina de $159,41 \mathrm{~mm}$ emergiu 13,67 folhas no mesmo período ou 0,98 folhas por dia. Por outro lado, dos 42 aos 55 DAS às plantas irrigadas com $\mathrm{L}_{1}(159,41$ $\mathrm{mm})$ apresentaram a segunda maior emergência de folhas, 1,95 folhas por dia enquanto na $L_{5}(372,83 \mathrm{~mm})$ as plantas, não induzidas pelo estresse hídrico, deixaram de emitir novas folhas, fato justificado por estas plantas terem começado o florescimento e frutificação primeiro que as demais. Esta justificativa fica mais plausível ao se observar o comportamento do número de folhas durante todo período de avaliação, ou seja, dos 27 aos 55 DAS, onde se nota que o número de folhas emitidas por dia foi em média $1,46,1,74,1,47,1,01$ e 0,79 para as plantas irrigadas com $\mathrm{L}_{1}, \mathrm{~L}_{2}, \mathrm{~L}_{3}, \mathrm{~L}_{4} \mathrm{e} \mathrm{L}_{5}$, respectivamente.

Ao que se refere à frequência de aplicação de água, nota-se pela Tabela 1, que na época de formação e enchimento dos frutos (55 DAS), a $\mathrm{F}_{2}$ (Lâmina de irrigação total parcelada em duas vezes ao dia) foi a mais eficaz em produzir folhas, chegando a produzir 75,53 folhas por planta, esta frequência também apresenta a maior variação entre a $1^{\mathrm{a}}$ e $3^{\mathrm{a}}$ avaliações sendo de 


\section{LÂMINAS DE IRRIGAÇÃO E FREQUÊNCIA DE APLICAÇÃO NO CRESCIMENTO DO MELOEIRO}

aproximadamente 209\%; por outro lado na época inicial do desenvolvimento da planta (27 DAS), quando aplicado à lâmina de irrigação total em uma única vez, produziu maior número de folhas (26 folhas/planta); ao passo em que o maior ganho de folhas no período da $1^{\mathrm{a}}$ e $2^{\mathrm{a}}$ avaliações foi registrado na frequência $F_{1}$ (Lâmina parcelada em três vezes ao dia), pelo comportamento é possível afirmar que a produção de folhas é indiferente à forma de como se aplica a água.

Segundo o modelo de regressão obtido para os 41 DAS (Figura 1), a área foliar cresceu quadraticamente com o aumento da lâmina de irrigação, havendo um crescimento de $2975,60 \mathrm{~cm}^{2} /$ planta no tratamento de menor lâmina $\left(\mathrm{L}_{1}=159,41\right.$ $\mathrm{mm}$ ) até $5380,99 \mathrm{~cm}^{2}$ planta $^{-1}$ na lâmina de $372,38 \mathrm{~mm}$, representando um incremento de $80,84 \%$. A partir do ponto de máxima área foliar $5579,02 \mathrm{~cm}^{2} /$ planta alcançado com uma lâmina de $326,41 \mathrm{~mm}$ até a maior lâmina estudada, registra-se um leve decréscimo de 3,55\% na área foliar (AF).

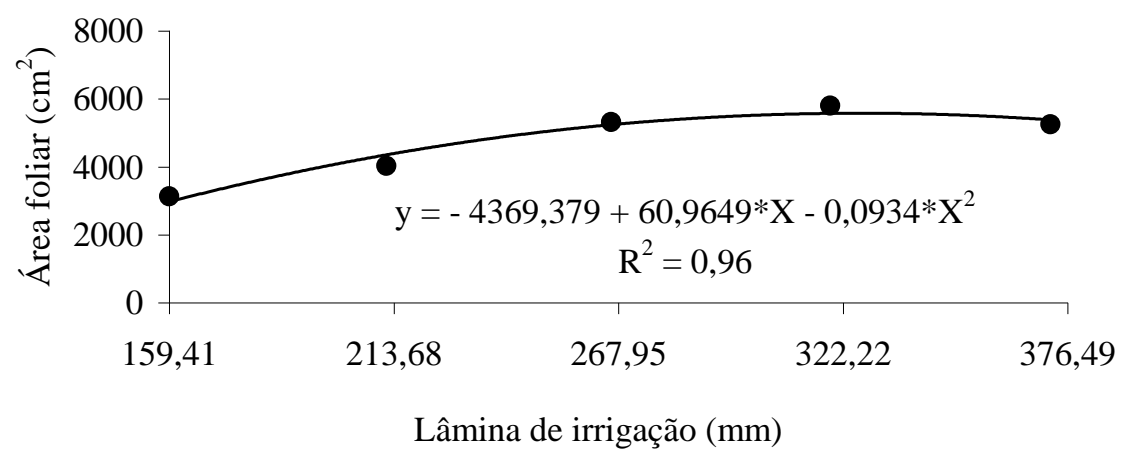

Figura 1. Área foliar do meloeiro var. inodoro do tipo "amarelo" cultivar híbrida F1 10/00, em função da lâmina de água, aos 41 dias após semeadura (DAS).

Nas demais épocas de avaliações, 27 e 55 DAS, nota-se pelas médias contidas na Tabela 1 que aos 27 DAS a maior área foliar obtida foi nas plantas irrigadas com $\mathrm{L}_{4}$, crescendo diariamente cerca de 103,62 $\mathrm{cm}^{2} /$ planta, enquanto que no maior suprimento hídrico o crescimento diário foi de $64,23 \mathrm{~cm}^{2} /$ planta, um decréscimo entre as lâminas $\mathrm{L}_{4}$ e $\mathrm{L}_{5}$ de $38,01 \%$; ao se comparar o tratamento de maior suprimento hídrico com o de maior déficit hídrico, nota-se que neste último a área foliar foi 1,58 vezes maior que na primeira condição. Aos 55 DAS, a área foliar obtida com a lâmina equivalente $100 \%$ da evapotranspiração local $(266,19 \mathrm{~mm})$, foi a maior com $6099,55 \mathrm{~cm}^{2} /$ planta superando a $\mathrm{L}_{5}$ em 30,54\%. Enquanto que nas duas medições anteriores os maiores valores foram observados na lâmina $\mathrm{L}_{4}(319,10)$. Ao contrário do que ocorreu com a área foliar dos 27 aos 41 DAS, o aumento diário da área foliar dos 42 aos 55 DAS foi decrescente a medida que aumentava o suprimento de água para as plantas.

De forma análoga à variável número de folhas, a frequência de aplicação d'água total em duas vezes ao dia $\left(\mathrm{F}_{2}\right)$ foi a que obteve melhor performance em área foliar no estádio de formação e enchimento dos frutos, chegando a $6191,28 \mathrm{~cm}^{2} /$ planta. Já o menor valor para esta característica ocorreu quando se aplicou a lâmina de irrigação total parcelada em três vezes ao dia $\left(\mathrm{F}_{1}\right)$, sendo de $4058,10 \mathrm{~cm}^{2} /$ planta, na mesma época.

Verifica-se pela análise de variância (Tabela 1), não ter havido efeito significativo $(\mathrm{p}<0,01)$ tanto de lâminas, quanto de frequência de aplicação da água sobre o acúmulo de matéria seca da parte aérea (MSPA) nas diferentes épocas de avaliação, assim como, sem efeito interativo dos fatores.

De acordo com as médias (Tabela 1), a matéria seca da parte aérea aumentou de 


\section{LÂMINAS DE IRRIGAÇÃO E FREQUÊNCIA DE APLICAÇÃO NO CRESCIMENTO DO MELOEIRO}

12,20 para 22,35 g planta ${ }^{-1}$, na menor lâmina $(159,41 \mathrm{~mm})$ dos 27 aos 55 DAS, resultando num incremento de 83,20\%; analogamente, verificamos ganhos na MSPA da ordem de 90,84\%, 94,36\%, $92,17 \%)$ e $100,57 \%$ quando foram aplicados os volumes totais de 211,92, $266,19, \quad 319,10$ e $372,38 \mathrm{~mm}$, respectivamente. Nota-se desta forma que o déficit hídrico não prejudicou a acumulação de matéria seca da parte aérea da planta. Por outro lado, o excesso de água aplicada representado aqui pelas lâminas $\mathrm{L}_{4} \mathrm{e} \mathrm{L}_{5}$ interferiu negativamente na MSPA dos 42 aos 55 DAS apresentando respectivamente decréscimos de $8,56 \mathrm{e}$ $28,68 \%$.

Nota-se que a lâmina considerada ideal $266,19 \mathrm{~mm}$ ou 1,0 $\mathrm{ETc}_{\mathrm{L}}$ foi a que apresentou melhor inversão no que concerne a produção de matéria seca da parte aérea, superando as demais lâminas nas avaliações de 27 e 55 DAS com os valores respectivos de 13,80 e 26,82 $\mathrm{g} \mathrm{planta}^{-1}$, chegando a produzir no intervalo entre a $1^{\mathrm{a}}$ e $2^{\mathrm{a}}$ medições um total acumulado de 12,20 $\mathrm{g}$ planta $^{-1}$ nos 14 dias do intervalo, correspondendo a um ganho real de $0,87 \mathrm{~g} \mathrm{planta}^{-1} \mathrm{dia}^{-1}$. Contudo, experimenta no período subsequiente, 41 a 55 DAS, queda neste ganho passando para 0,06 g planta $^{-1}$.

A lâmina de maior déficit hídrico $159,41 \mathrm{~mm}$ apresentou o menor incremento de matéria seca na amplitude total de avaliação sendo de 83,20\%. Já a lâmina de 211,92 mm, a exemplo da lâmina 266,19 $\mathrm{mm}$, teve aumento na matéria seca da parte aérea nos dois intervalos de tempo, sendo de 9,16 e 2,55 g planta $^{-1}$ para o período de 27 aos 41 DAS e de 42 aos 55 DAS, respectivamente, o que equivale a $0,65 \mathrm{e}$ 0,18 g planta $^{-1}$ dia $^{-1}$ (Figura 2). Já dos 42 aos 55 DAS as plantas irrigadas com $\mathrm{L}_{4} \mathrm{e} \mathrm{L}_{5}$ (319,10 e 372,38 mm) deixaram de acumular matéria seca, fato justificado por estas plantas terem começado o florescimento e frutificação primeiro que as demais e muito provavelmente translocaram o incremento destinado à matéria seca para os frutos.

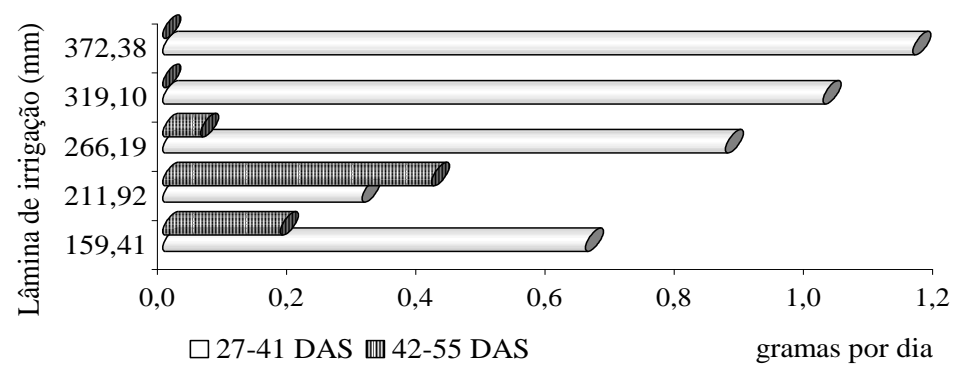

Figura 2. Aumento diário da matéria seca da parte aérea do meloeiro var. inodoro do tipo "amarelo" cultivar híbrida F1 10/00 nas diferentes lâminas de irrigação.

A aplicação da lâmina de irrigação total parcelada em duas vezes ao dia foi a que apresentou maior acúmulo de matéria seca da parte aérea (Tabela 1) aos 55 DAS, produzindo $28,34 \mathrm{~g}_{\text {planta }}{ }^{-1}$, enquanto que a aplicação d'água fracionada em três vezes ao dia $\left(\mathrm{F}_{1}\right)$ alcançou o menor rendimento com 17,54 g planta $^{-1}$. Concordando com Ferreira \& Pedrosa (1982) ao relatarem que o meloeiro exige água de forma moderada no solo no período da germinação ao crescimento inicial. Após esse período, durante o crescimento dos frutos, diminui- se gradativamente a frequência das irrigações e, ao iniciar-se a maturação dos frutos, mantém-se o solo com baixa umidade antes da colheita, garantindo, desta maneira, a qualidade dos frutos. Os dados de matéria seca da parte aérea obtida neste experimento foram maiores que os de Farias et al (2003), em todas as lâminas utilizadas por eles.

De acordo com a análise de variância (Tabela 2), não houve efeito dos fatores lâminas (L), frequência de aplicação de água $(\mathrm{F})$, e na interação destes, sobre o 


\section{LÂMINAS DE IRRIGAÇÃO E FREQUÊNCIA DE APLICAÇÃO NO CRESCIMENTO DO MELOEIRO}

acúmulo de matéria seca do pecíolo (MSP) e das flores (MSFL) nas três épocas avaliadas, exceto aos 41 DAS para o primeiro fator. Segundo as médias obtidas (Tabela 2), a matéria seca do pecíolo passou de $1,69,2,41$ e $2,70 \mathrm{~g}_{\text {planta }}{ }^{-1}$ na menor lâmina $(159,41 \mathrm{~mm})$, para 1,87 , 3,94 e 3,55 g planta $^{-1}$, no ponto de máxima produção de matéria seca do pecíolo, correspondente a lâmina padrão de $100 \%$ da evapotranspiração local da cultura $\left(\mathrm{ETc}_{\mathrm{L}}\right)$, ou 266,19 $\mathrm{mm}$; esse aumento favoreceu um incremento de 10,65, 63,48 e $31,48 \%$, aos 27,41 e 55 DAS, respectivamente, evidenciando que o déficit hídrico ocasiona redução do crescimento da planta.

Tabela 2. Resumo das análises de variância referentes à matéria seca do pecíolo, das flores, das folhas e do caule do meloeiro var. inodoro do tipo "amarelo" cultivar híbrida F1 10/00,irrigado com diferentes lâminas e diferentes frequência de aplicação da água em diferentes épocas

\begin{tabular}{|c|c|c|c|c|c|c|c|c|c|c|c|c|c|}
\hline \multirow{4}{*}{ Causa de variação } & \multirow{4}{*}{ GL } & \multicolumn{12}{|c|}{ Quadrados médio } \\
\hline & & \multicolumn{3}{|c|}{ Pecíolo } & \multicolumn{3}{|c|}{ Flores } & \multicolumn{3}{|c|}{ Folha } & \multicolumn{3}{|c|}{ Caule } \\
\hline & & \multicolumn{3}{|c|}{ DAS } & \multicolumn{3}{|c|}{ DAS } & \multicolumn{3}{|c|}{ DAS } & \multicolumn{3}{|c|}{ DAS } \\
\hline & & $27^{1}$ & $41^{1}$ & $55^{1}$ & $27^{1}$ & $41^{1}$ & $55^{1}$ & $27^{1}$ & $41^{1}$ & $55^{1}$ & $27^{1}$ & $41^{1}$ & $55^{1}$ \\
\hline Lâmina de irrigação (L) & 4 & $0,07^{\mathrm{NS}}$ & $0,42 *$ & $0,10^{\mathrm{NS}}$ & $0,002^{\mathrm{NS}}$ & $0,002^{\mathrm{NS}}$ & $0,004^{\mathrm{NS}}$ & $0,57^{\mathrm{NS}}$ & $1,45^{\mathrm{NS}}$ & $0,78^{\mathrm{NS}}$ & $0,24^{\mathrm{NS}}$ & $0,45^{\mathrm{NS}}$ & $0,36^{\mathrm{NS}}$ \\
\hline Frequência de aplicação (F) & 3 & $0,01^{\mathrm{NS}}$ & $0,03^{\mathrm{NS}}$ & $0,19^{\mathrm{NS}}$ & $0,002^{\mathrm{NS}}$ & $0,001^{\mathrm{NS}}$ & $0,005^{\mathrm{NS}}$ & $0,01^{\mathrm{NS}}$ & $0,19^{\mathrm{NS}}$ & $1,14^{\mathrm{NS}}$ & $0,02^{\mathrm{NS}}$ & $0,06^{\mathrm{NS}}$ & $0,76^{\mathrm{NS}}$ \\
\hline Interação L X F & 12 & $0,07^{\mathrm{NS}}$ & $0,08^{\mathrm{NS}}$ & $0,18^{\mathrm{NS}}$ & $0,001^{\mathrm{NS}}$ & $0,001^{\mathrm{NS}}$ & $0,001^{\mathrm{NS}}$ & $0,45^{\mathrm{NS}}$ & $0,30^{\mathrm{NS}}$ & $0,88^{\mathrm{NS}}$ & $0,16^{\mathrm{NS}}$ & $0,10^{\mathrm{NS}}$ & $0,26^{\mathrm{NS}}$ \\
\hline Bloco & 2 & $0,34 * *$ & $0,08^{\mathrm{NS}}$ & $0,03^{\mathrm{NS}}$ & $0,007 * *$ & $0,001^{\mathrm{NS}}$ & $0,002^{\mathrm{NS}}$ & $1,43 * *$ & $0,23^{\mathrm{NS}}$ & $0,16^{\mathrm{NS}}$ & $0,89 * *$ & $0,17^{\mathrm{NS}}$ & $0,19^{\mathrm{NS}}$ \\
\hline Resíduo & 38 & 0,06 & 0,14 & 0,23 & 0,001 & 0,001 & 0,003 & 0,35 & 0,61 & 1,27 & 0,19 & 0,27 & 0,55 \\
\hline \multirow[t]{2}{*}{$\mathrm{CV}$} & $\%$ & 15,57 & 17,79 & 24,72 & 3,38 & 2,88 & 5,21 & 20,88 & 20,86 & 29,61 & 22,75 & 19,83 & 29,94 \\
\hline & & \multicolumn{12}{|c|}{ Médias observadas $^{2}$} \\
\hline Lâmina de irrigação & & \multicolumn{12}{|c|}{ - } \\
\hline $\mathrm{L}_{1}(159,41 \mathrm{~mm})$ & & 1,69 & 2,41 & 2,70 & 0,09 & 0,15 & 0,11 & 7,41 & 9,51 & 13,89 & 3,02 & 4,47 & 5,64 \\
\hline $\mathrm{L}_{2}(211,92 \mathrm{~mm})$ & & 1,77 & 3,02 & 2,80 & 0,07 & 0,13 & 0,17 & 7,88 & 13,15 & 15,11 & 3,17 & 5,76 & 6,52 \\
\hline $\mathrm{L}_{3}(266,19 \mathrm{~mm})$ & & 1,87 & 3,94 & 3,55 & 0,08 & 0,19 & 0,15 & 8,41 & 15,25 & 16,79 & 3,44 & 6,62 & 6,33 \\
\hline $\mathrm{L}_{4}(319,10 \mathrm{~mm})$ & & 1,82 & 4,19 & 3,48 & 0,10 & 0,16 & 0,10 & 7,97 & 15,94 & 15,68 & 3,10 & 7,03 & 5,70 \\
\hline $\mathrm{L}_{5}(372,38 \mathrm{~mm})$ & & 1,29 & 4,14 & 2,61 & 0,04 & 0,20 & 0,08 & 5,51 & 14,27 & 11,23 & 2,13 & 6,63 & 4,08 \\
\hline dms & & 0,97 & 1,83 & 2,59 & 0,08 & 0,08 & 0,14 & 3,99 & 6,73 & 11,39 & 2,06 & 3,20 & 5,01 \\
\hline Frequência de aplicação & \multicolumn{13}{|c|}{ 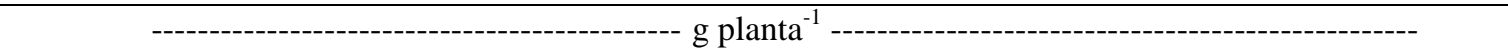 } \\
\hline $\mathrm{F}_{1}(3$ vezes ao dia) & & 1,60 & 3,71 & 2,32 & 0,10 & 0,15 & 0,09 & 7,39 & 14,01 & 11,20 & 2,92 & 5,94 & 3,93 \\
\hline $\mathrm{F}_{2}(2$ vezes ao dia $)$ & & 1,70 & 3,30 & 3,55 & 0,05 & 0,17 & 0,18 & 7,41 & 12,61 & 17,35 & 2,89 & 5,84 & 7,27 \\
\hline $\mathrm{F}_{3}(1 \mathrm{vez}$ ao dia $)$ & & 1,67 & 3,39 & 2,91 & 0,07 & 0,18 & 0,10 & 7,46 & 13,17 & 15,05 & 3,18 & 5,93 & 5,60 \\
\hline $\mathrm{F}_{4}($ dias alternados $)$ & & 1,77 & 3,75 & 3,33 & 0,09 & 0,15 & 0,13 & 7,49 & 14,70 & 14,57 & 2,91 & 6,69 & 5,82 \\
\hline dms & & 0,81 & 1,53 & 2,18 & 0,07 & 0,07 & 0,12 & 3,35 & 5,65 & 9,57 & 1,72 & 2,69 & 4,21 \\
\hline
\end{tabular}

$\mathrm{NS}=$ não significativo; $*$ =significativo a $5 \%$ de probabilidade $\mathrm{e}^{* *}=$ significativo a $1 \%$ de probabilidade pelo Teste F. ${ }^{1}$ dados transformados em $\sqrt{X+1} ;{ }^{2}$ médias originais.

Por sua vez, o excesso de água também prejudicou o crescimento; conforme as médias, a matéria seca dos pecíolos acumulada no tratamento de maior suprimento hídrico $(372,38 \mathrm{~mm})$, aos 27 e 55 DAS é 31,02 e 26,48\% menor que a MSP alcançada com a lâmina padrão. Com relação à matéria seca das flores (MSFL), segundo as médias observadas, nota-se que aos 27 DAS o maior acúmulo de matéria seca se deu na lâmina de $319,10 \mathrm{~mm}(0,10 \mathrm{~g}$ planta $\left.^{-1}\right)$, aos 41 DAS na lâmina de maior suprimento hídrico $\left(0,20 \mathrm{~g}\right.$ planta $\left.^{-1}\right)$ e aos 55 DAS na lâmina de $211,19 \mathrm{~mm}(0,17 \mathrm{~g}$ planta $\left.^{-1}\right)$; demonstrando que as plantas irrigadas com uma lâmina de $372,38 \mathrm{~mm}$ $\left(\mathrm{L}_{5}\right)$, antecipam a sua floração, visto que, essas plantas dos 27 aos 41 DAS, a MSFL cresceram $0,011 \mathrm{~g} \mathrm{planta}^{-1}$ ao dia, enquanto

as irrigadas com $\mathrm{L}_{1}, \mathrm{~L}_{2}, \mathrm{~L}_{3}$ e $\mathrm{L}_{4}$, aumentaram neste mesmo período 0,004, 0,004, 0,007 e $0,004 \mathrm{~g} \mathrm{planta}^{-1}$ ao dia, respectivamente. 


\section{LÂMINAS DE IRRIGAÇÃO E FREQUÊNCIA DE APLICAÇÃO NO CRESCIMENTO DO MELOEIRO}

Pela Figura 3A observa-se que do período de 27 até 41 DAS, a medida que aumentou o suprimento hídrico mais gramas por dia as plantas ganharam em relação a matéria seca do pecíolo, contrariamente ao período dos 42 aos 55 DAS, que apenas na lâmina de $159,41 \mathrm{~mm}$ verificou incremento diário de MSP. Na matéria seca das flores, o incremento de matéria seca diário foi maior nas lâminas $\mathrm{L}_{5}$ e $\mathrm{L}_{3}$ e as demais lâminas mantiveram um ganho idêntico dos 27 aos 41 DAS (Figura 3B), já dos 42 aos 55 DAS, apenas as plantas irrigadas com a lâmina de 211,92 $\mathrm{mm}$ apresentou aumento diário da matéria seca das flores.
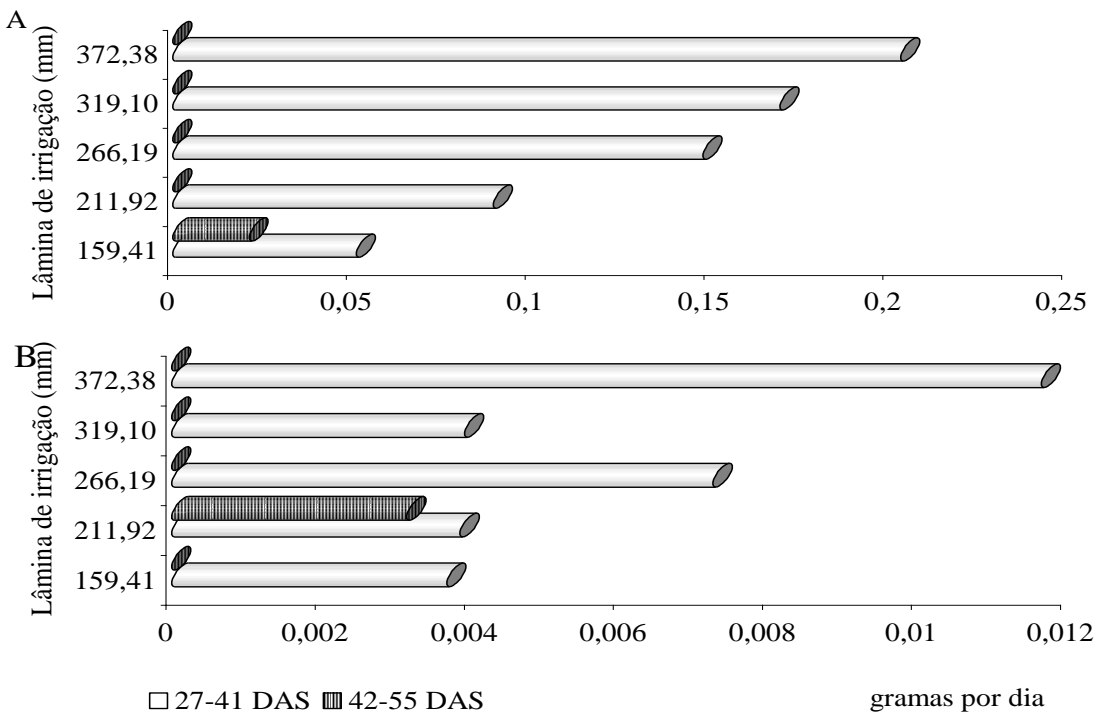

Figura 3. Aumento diário da matéria seca do pecíolo (A) e das flores (B) do meloeiro var. inodoro do tipo "amarelo" cultivar híbrida F1 10/00 nas diferentes lâminas de irrigação.

De acordo com a análise de variância dos dados de matéria seca das folhas (MSFH) aos 27, 41 e 55 DAS (Tabela 2), não houve efeito, significativo em nível de $1 \%$ de probabilidade, para as lâminas de irrigação e frequência de aplicação de água, assim como na interação. Observa-se pela Tabela 2 que nas avaliações de 27 e 55 DAS o maior acúmulo de matéria seca das folhas se deu nas plantas irrigadas com a lâmina de 266,19 mm, que corresponde a $100 \%$ da evapotranspiração local da cultura $\left(\mathrm{ETc}_{\mathrm{L}}\right)$; nota-se também que até aplicação deste nível de fornecimento d'água o acúmulo.de matéria seca foi crescente nas três épocas avaliadas, enquanto que nas frações de 1,2 e 1,4 $\mathrm{ETc}_{\mathrm{L}}$ houve um decréscimo dos 41 aos 55 DAS, provavelmente, devido as plantas irrigadas com esses volumes d'água terem entrado mais cedo no processo de senescência, visto que o maior índice de emissão de flores nestes tratamentos foram alcançados aos 41 DAS.

$\mathrm{Na}$ matéria seca do caule (MSC), também se observa efeito não significativo para os fatores lâminas de irrigação, frequência de aplicação de água e para a interação L x F. Porém nota-se nas médias que apenas em $\mathrm{L}_{1}$ e $\mathrm{L}_{2}$, lâminas de menor suprimento hídrico, o acúmulo de matéria seca foi crescente nas três épocas avaliadas, apresentando na $\mathrm{L}_{1}$ um incremento de 48,01 e $26,17 \%$ dos 27 aos 41 e dos 42 aos 55 DAS, respectivamente; na $\mathrm{L}_{2} \mathrm{o}$ aumento foi de $81,70 \%$ e $13,19 \%$ respectivos aos mesmos períodos. Nas lâminas de 266,19 $\mathrm{mm}\left(\mathrm{L}_{3}\right), 319,10 \mathrm{~mm}\left(\mathrm{~L}_{4}\right)$ e $372,38 \mathrm{~mm}$ $\left(\mathrm{L}_{5}\right)$, observou-se um acréscimo na MSC apenas entre os 27 e 41DAS, de 92,44, 126,77 e $211,27 \%$ para $\mathrm{L}_{3}, \mathrm{~L}_{4}$ e $\mathrm{L}_{5}$, respectivamente (Tabela 2 ).

Observa-se na Figura 4 que o incremento diário de matéria seca das 


\section{LÂMINAS DE IRRIGAÇÃO E FREQUÊNCIA DE APLICAÇÃO NO CRESCIMENTO DO MELOEIRO}

folhas em todo período avaliado foi maior que o do caule e que dos 27 aos 41 DAS as plantas diariamente acumularam mais matéria seca, tanto das folhas como do caule, à medida que acrescentava a lâmina de irrigação (Figura 4), o mesmo não ocorrendo no período de 42 aos 55 DAS, onde se verificou decréscimo no incremento diário da matéria seca, apresentando ligeiro aumento da MSFH somente até a lâmina de 266,19 mm (Figura 4A) enquanto que na MSC esse ganho só foi registrado até o nível d'água anterior $(211,92 \mathrm{~mm})$, Figura 5A. Em face disto, infere-se que os fotoassimilados produzidos pela planta do meloeiro são translocados para as folhas enquanto, dreno principal, e depois com o aparecimento dos frutos, estes tem primazia pelos fotoassimilados.
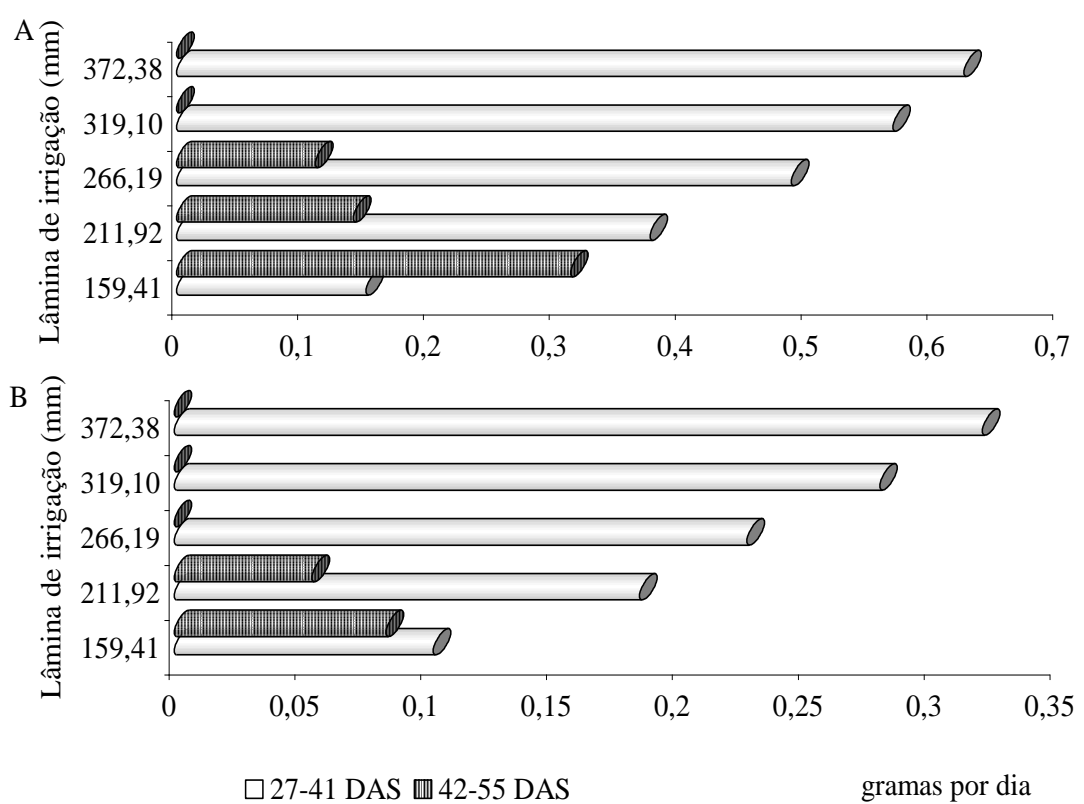

Figura 4. Aumento diário da matéria seca das folhas (A) e do caule (B) do meloeiro var. inodoro do tipo "amarelo" cultivar híbrida F1 10/00 nas diferentes lâminas de irrigação.

Conforme Taiz \& Zeiger (2004), a expansão ou alongamento celular, é um processo dependente do turgor, portanto, é extremamente sensível à disponibilidade de água no solo para as plantas; assim, a restrição hídrica limita não só o tamanho, mas também o número de folhas; fatos evidenciados na presente pesquisa. Ademais, segundo esses autores, as folhas desenvolvem uma cutícula mais grossa para reduzir a perda de água por transpiração. Estas medidas aumentam a eficiência de uso de água (EUA) pela planta, como pode ser constatado posteriormente, pela relação inversa entre lâmina de água fornecida às plantas e o valor correspondente obtido para EUA. Segundo Bergamaschi (1999), a baixa disponibilidade de água no solo pode provocar redução da área foliar, por secamento ou queda das folhas, uma tentativa da planta reduzir a perda de água por transpiração, aumentando a eficiência de uso da água; todavia, isto resulta em queda da fotossíntese total, que por sua vez reduz a taxa de crescimento e a produção da planta.

\section{CONCLUSÕES}

Os fatores lâminas e frequência de irrigação foram indiferentes à característica número de folhas; A lâmina fez efeito na variável área foliar apenas aos 41 DAS, no entanto, até este dia de medição, observouse, efeito crescente com o aumento do fornecimento d'água e decrescente a partir deste; A maior produção de matéria seca 


\section{LÂMINAS DE IRRIGAÇÃO E FREQUÊNCIA DE APLICAÇÃO NO CRESCIMENTO DO MELOEIRO}

pelo meloeiro está condicionada as maiores lâminas de irrigação; $\mathrm{O}$ maior e o menor incremento de matéria seca, foram obtidos nas plantas irrigadas com as lâminas de

\section{REFERÊNCIAS BIBLIOGRÁFICAS}

ALLEN, R.G.; PEREIRA, L.S.; RAES, D.; SMITH, M. Crop evapotranspiration: guidelines for computing crop water requirements. Rome: FAO. Irrigation and Drainage Paper, 56, 1998. 300 p.

BENINCASA, M. M. P. Análise de crescimento de plantas. Jaboticabal: FUNEP, 1988. 42p.

BERGAMASCHI, H. . Desenvolvimento de déficit hídrico em culturas. In: BERGAMASCHI, H. (Coord.) e outros. (Org.). Agrometeorologia aplicada à irrigação. 2a. ed. Porto Alegre: Editora da Universidade/UFRGS, 1999

CAMPELO, A. R.; AZEVEDO, B. M. de; NASCIMENTO NETO, J. R. do; FERNANDES, C. N. V. Manejo da cultura do melão submetida à diferentes frequências de irrigação. In: Inovagri International Meeting, 1 e Workshop Internacional de Inovações Tecnológicas na Irrigação, 4. 2012, Fortaleza - CE. Anais...Fortaleza: INOV AGRI, 2012.

COELHO, E. F.; COELHO FILHO, M. A.; OLIVEIRA, S. L de. Agricultura irrigada: eficiência de irrigação e de uso de água. Bahia Agrícola., v.7, n.1, p.57- 60, 2005.

COSTA, N.D.; DIAS, R.C.S.; FARIA, C.M.B.; TAVARES, S.C.C.H.; TERAO, D. Petrolina-EMBRAPA. Empresa Brasileira de Pesquisa Agropecuária Semiárido, Avaliação de cultivares de cebola em Petrolina. Circular Técnica, 59, 2000. p.37-39.

DNOCS - Departamento Nacional de Obras Contra as Secas. Perímetro de Irrigação Baixo Acaraú. Disponível em: $<$ http://www.
266,19 e $159,41 \mathrm{~mm}$, respectivos a 94,36 e $83,20 \%$; O maior crescimento das plantas do meloeiro foi registrado aos 41 dias após a

dnocs.gov.br/ppi/ce/baixo_acarau.html>. Acessado em 25/05/2004. 2004.

EMBRAPA - EMPRESA BRASILEIRA DE PESQUISA AGROPECUÁRIA. Manual de métodos de análises de solo. 2.ed. Rio de Janeiro, Ministério da Agricultura e do Abastecimento, 1997. $212 p$.

FARIAS, C. D. DE A.; ESPÍNOLA SOBRINHO, J.; MEDEIROS, J F DE.; COSTA, M. C.; NASCIMENTO, I. B. DO.; SILVA, M. C. DE C. Crescimento e desenvolvimento da cultura do melão sob diferentes lâminas de irrigação e salinidade da água. Revista Brasileira de Engenharia Agrícola e Ambiental, v.7, n.3, p.445-450, 2003.

FERREIRA, F.A.; PEDROSA, J.F. Melão: cultivares e métodos culturais. Informe Agropecuário, v.8, n.85, p.26-28, 1982.

FERREIRA, P.V. Estatística experimental aplicada à agronomia. $2^{\mathrm{a}}$ ed. Maceió: EDUFAL, 2000. 422p.

MONTEIRO, R. O. C., COSTA, R. N. T., LEÃO, M. C. S., AGUIAR, J. V. de. Eficiência do uso da água e nitrogênio na produção de melão. Revista Irriga, Botucatu, v.13, n.3, p.367-377, 2008.

RIBEIRO JÚNIOR, J.I. Análise estatística no SAEG. Viçosa: UFV, 2001. 301p.

SANTOS A. A.; CRISÓSTOMO JR.; CARDOSO J. W. 2004. Avaliação de híbridos de melão quanto às principais doenças nos estados do Ceará e Rio Grande do Norte. Boletim de pesquisa e desenvolvimento, Fortaleza: Embrapa Agroindústria Tropical, 14p. 


\section{LÂMINAS DE IRRIGAÇÃO E FREQUÊNCIA DE APLICAÇÃO NO CRESCIMENTO DO MELOEIRO}

SILVA, J. N. da; FIGUEIREDO, J. P. de; FIGUEIREDO, L. F.; SILVA, T. H. da; ANDRADE, R. Influência de diferentes lâminas de irrigação no crescimento do meloeiro cantaloupe. In: Inovagri International Meeting, 1 e Workshop Internacional de Inovações Tecnológicas na Irrigação, 4. 2012, Fortaleza - CE. Anais...Fortaleza: INOVAGRI, 2012.

SOUSA, A. E. C.; BEZERRA, F. M. L.; SOUSA, C. H. C. de; SANTOS, F. S. S. dos. Produtividade do meloeiro sob lâmina de irrigação e adubação potássica. Engenharia Agrícola. Jaboticabal, v.30, n.2, p.271-278, 2010.

TAIZ, L.; ZIEGER, E. Fisiologia vegetal. $3^{\mathrm{a}}$ ed. Porto Alegre: Artmed, 2004. 719p.
TERCEIRO NETO, C. P. C.; MEDEIROS, J. F. de; GHEYI, H. R.; DIAS, N. da S.; OLIVEIRA, F. R. A. de; LIMA, K. da S. Acúmulo de matéria seca e nutrientes no meloeiro irrigado sob estratégias de manejo da salinidade. Revista Brasileira de Engenharia Agrícola e Ambiental, Campina Grande, v.16, n.10, p.1069-1077, 2012.

THORNTHWAITE, C. W.; MATHER, J. R. The water balance. Climatology, Centerton, NJ. v.8, n.1. 1955.

VALNIR JÚNIOR, M., SANTOS NETO, A. M., SOARES, F. A. L., LIMA, S. C. R. V., OLIVEIRA, M. S. F. de. Eficiência do uso da água nas características de produção do meloeiro. In: Congresso Brasileiro de Engenharia Agrícola, 38. 2009, Juazeiro BA. Anais... Juazeiro: SBEA, 2009. 